\title{
Supersonic Business Jet Conceptual Design in a Multidisciplinary Design Analysis Optimization Environment
}

\author{
Yicheng Sun ${ }^{1}$ and Howard Smith ${ }^{2}$ \\ Cranfield University, Bedford, MK43 OAL, UK
}

\begin{abstract}
This paper introduces a multidisciplinary design analysis and optimization (MDAO) environment called GENUS, which has been developing in Cranfield University's Aircraft Design Group. The GENUS aircraft design environment has the feature of modular, expandable, flexible, independent, sustainable, and performable. This paper discusses the application of this environment to supersonic business jets (SSBJs), which are regarded as the pioneer for the next generation of supersonic airliners. Methodologies appropriate to SSBJ are developed in the GENUS environment. Mach plane cross-sectional area is calculated based on the parametric geometry model. PANAIR is modified to do automated aerodynamic analysis. Drag coefficient is corrected by Harris wave drag calculation and form factor method. NASA EngineSim is integrated for engine modeling. Carlson simplified sonic boom prediction method has been used for sonic boom signature prediction. Results of the Cranfield E5 SSBJ are presented. Low-boom and low-drag SSBJ designs can be explored based on the framework.
\end{abstract}

\section{Nomenclature}

A $\quad=$ cross-sectional are

$\bar{c} \quad=$ mean aerodynamic chord

$C_{F} \quad=$ skin friction coefficient

$C_{L_{\alpha}} \quad=\quad$ lift coefficient curve slope

$C_{m_{\alpha}} \quad=$ moment coefficient curve slope

$D_{\text {wave }}=$ wave drag

$\mathrm{FF} \quad=$ form factor

$\mathrm{H}_{\mathrm{e}} \quad=$ energy height

$l=$ overall aircraft length

$p=$ overpressure

$\mathrm{P}_{\mathrm{s}} \quad=$ specific excess power

$S_{\text {ref }}=$ reference area

$S_{\text {wet }} \quad=$ wet area

$\mathrm{V}=$ aircraft velocity

$X_{a c} \quad=$ aerodynamic center on $\mathrm{x}$ axis

$X_{C G} \quad=$ center of gravity position on $\mathrm{x}$ axis

$Y_{C G} \quad=$ center of gravity position on $\mathrm{y}$ axis

$Z_{C G} \quad=$ center of gravity position on $\mathrm{z}$ axis

$\theta=$ angle between the $\mathrm{Y}$-axis and a projection onto the $\mathrm{Y}-\mathrm{Z}$ plane of a normal to the Mach plane

$\rho \quad=$ air density

\section{Introduction}

LL aerospace vehicle design methods tend to gravitate towards computer integrated design environments. Design environments enable modular implementation of the aircraft design process, which has two main

\footnotetext{
${ }^{1}$ Ph.D. student, School of Aerospace Transport and Manufacturing, AIAA Student Member.

${ }^{2}$ Professor, School of Aerospace Transport and Manufacturing, AIAA Senior Member.
} 
benefits. First of all, it enables specialists to develop methods covering their field in detail, without the need to understand and know everything else in the process. Second, but perhaps even more important, that it enables the reuse of methods, thus takes away the need to 'reinvent the wheel' over and over again. This proves to be a particular problem at university level, as often students spend most of their available time developing methods, and have very little chance to actually understand the outcome, or analyze the special features in more detail. An example to put this more into perspective, method is developed to represent geometry every time a new aircraft design process is started. Ultimately however, all these methods converge to a fairly similar solution, especially for conventional aircraft shapes. Although there is academic value in understanding this process, it could take away weeks or months from the available project time. If the focus of the project is not geometry related, it is definitely not beneficial. To overcome the issue, a multidisciplinary design analysis and optimization (MDAO) environment was developed in Cranfield University's Aircraft Design Group [1]. The GENUS aircraft design environment has been applied to a hypersonic space design [2], a solar UAV design [3], and a blended-wing body (BWB) design [4]. A turbofan airliner model [5] was used to validate the environment.

There has been a renewed, worldwide interest in developing an environmentally friendly, economically viable and technologically feasible supersonic transport aircraft. A historical overview indicates that the supersonic business jet (SSBJ) will be the pioneer for the next generation of supersonic airliners [6, 7]. To mitigate the sonic boom intensity vital if the vehicle is to be permitted to operate over land and hence be economically friendly. Besides, improving the aerodynamic efficiency will decrease the fuel consumption and hence be economically viable. Many technical aspects have influence on the aircraft performance. Therefore, a practical MDAO environment with proper methods is necessary for SSBJ design space exploration.

This paper is organized as follows: Section III gives an overview of the design philosophy and disciplinary models of the MDAO environment. Section IV describes detailed architecture of each module and the appropriate methods to model SSBJ concepts. Section V contains the analysis and optimization results for a SSBJ case. The last section discusses the conclusions and future work.

\section{Overview of the GENUS Aircraft Design Environment}

The multidisciplinary design analysis and optimization aircraft conceptual design environment is named GENUS. The word 'genus' comes from either the Latin term genus (descent or family) or the Greek word genos (race, kin). It is used by biologists as a taxonomic rank to classify organisms; Genus is positioned above the rank of species and below the rank of family in the hierarchy. For us, the name signifies the connection between the various 'species' of aerospace vehicles, and the design environment's ability to encompass the design methods for all of them. The position of Genus in diverse aircraft conceptual design is shown in Fig. 1.

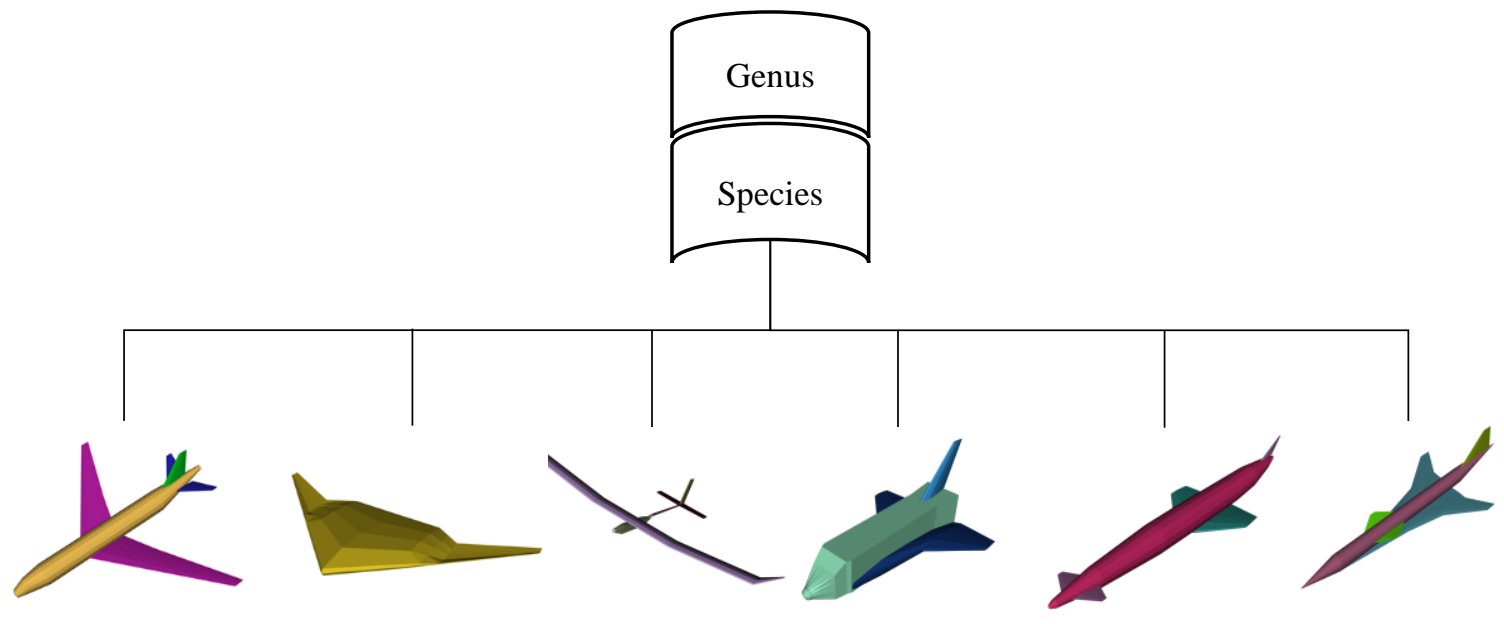

Fig. 1. Position of Genus in diverse aircraft conceptual design

The GENUS environment was envisioned by Professor Howard Smith, head of the Aircraft Design Group. The high-level requirements for this aircraft conceptual design environment are modular, expandable, flexible, independent, sustainable, and performable.

As it is the aim of GENUS Aircraft Conceptual Design environment to provide a modular, flexible framework both for designers to use existing, and for researchers to develop new methods for aerospace vehicle design. GENUS 
is coded in JAVA and does not rely on any of the commercial codes. After evaluating various design systems, methodologies and approaches, nine essential modules (Fig. 2) are identified, that are required to synthesize and analyze most aerospace vehicle concepts. The modules are linked together tightly, which makes the multidiscipline design optimization possible.

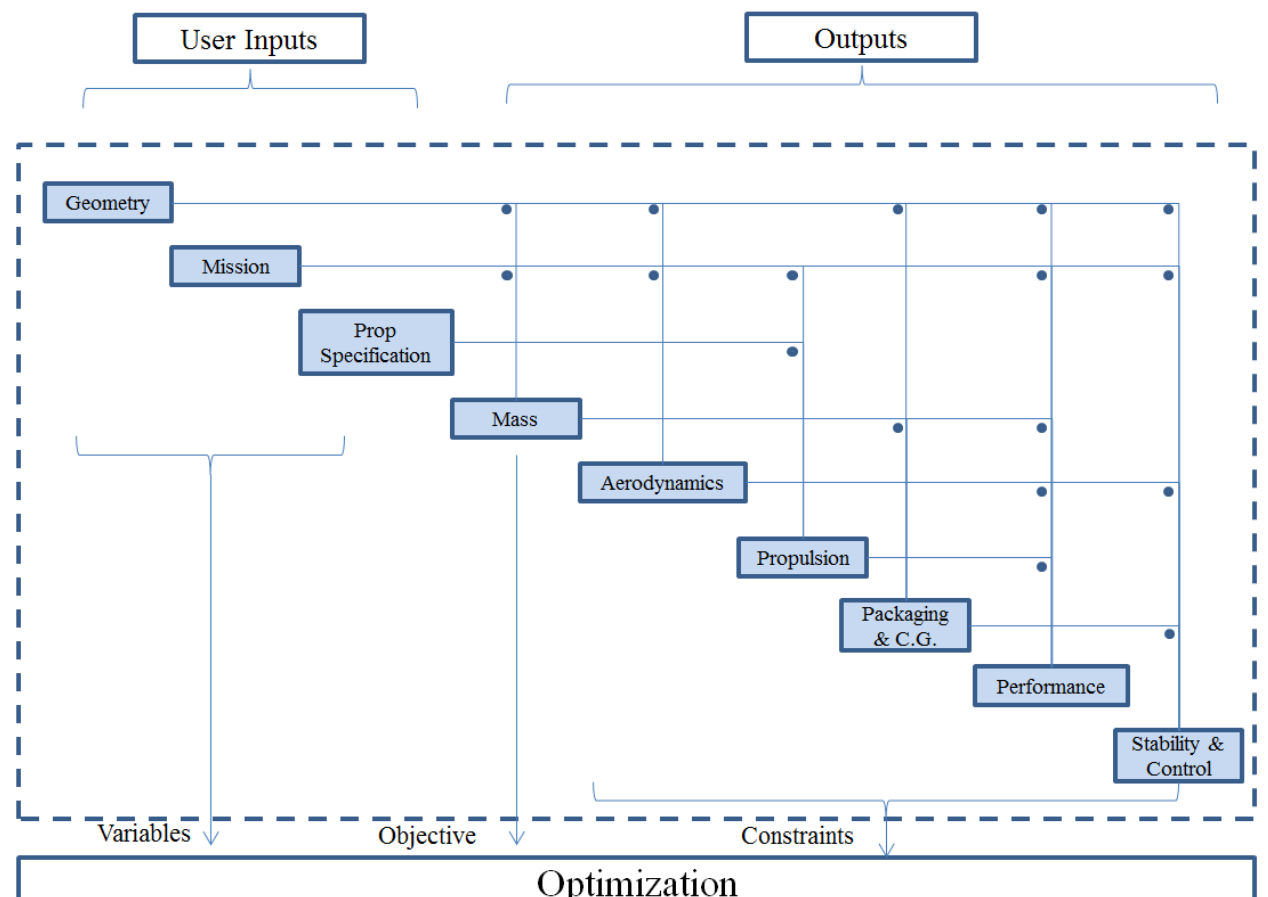

Fig. 2. Modules and data flow of GENUS

\section{SSBJ Design Analysis and Optimization Methodologies}

An integrated process for multi-fidelity multidisciplinary design analysis and optimization for low-boom and low-drag supersonic business jets has been completed. This integrated process includes all the above essential modules. Sonic boom prediction is added as a special key module in the process.

\section{A. Geometry Generation}

The geometry module aims to cover most of the configurations with a generic setting. The geometry parts are abstracted into lifting surface array and body component array. The lifting surface array is then specified as wing, horizontal tail, vertical tail or canard. The body component array is specified as fuselage, engine pod, external tank or tail boom. The hierarchy of the geometry module is defined in Fig. 3. The length of the two arrays can be any integer depending on the aircraft configuration. A zero-long body component array is applicable to a flying wing type aircraft, whereas a zero long lifting surface array could represent a space capsule. The inputs for geometry are designed to be intuitive to users. An illustration of the geometry variable definitions can be found in Ref. [2]. Users can preset input variables value inside the code, so that when running the same configuration, there is no need to input the same value every time. 


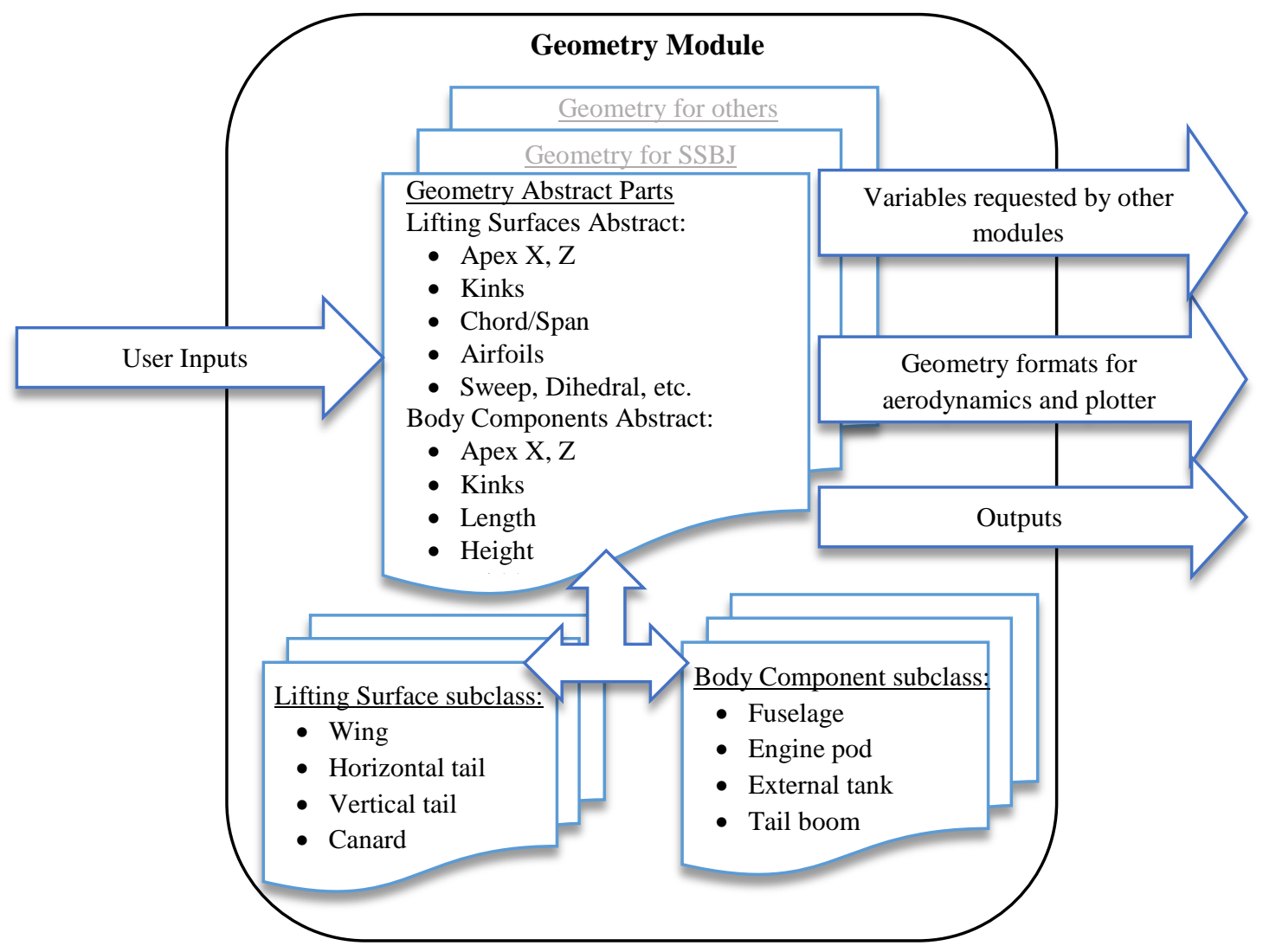

Fig. 3. Hierarchy and data flow of geometry module

The geometry generation module is the foundation of the MDAO environment because it is critical to the analysis of the external (aerodynamics and sonic boom) and internal (mass breakdown and packaging) configuration. The geometry is generated by VTK (Visualization Toolkit), which is an open source software for 3D computer graphics.

\section{B. Mission Profile}

The mission module specifies several flight requirements for a design. These requirements are derived from the market or customer specifications. There are a set of variables defined in the abstract class. Designers can add their own mission variables in the subclass. These variables will be used in the subsequent modules. The module hierarchy is shown in Fig. 4. The mission variables can be set to cover all the mission profile points if necessary. Users can also preset input values in the code. 


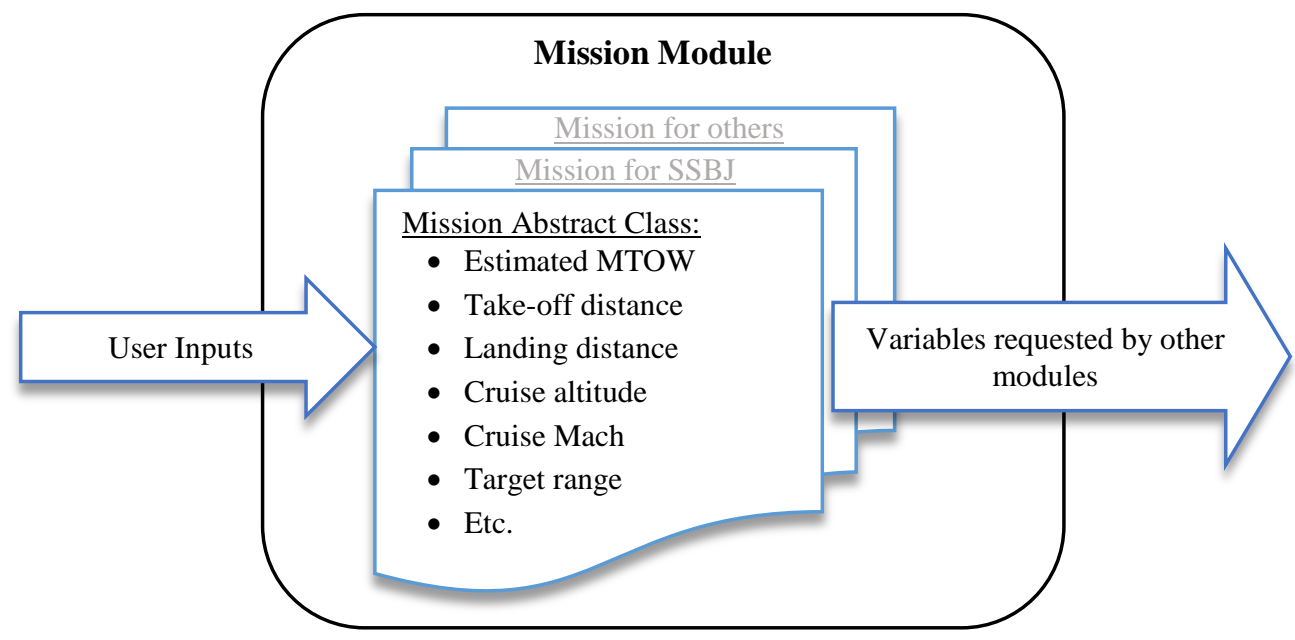

Fig. 4. Hierarchy and data flow of mission module

The mission requirements (Table 1) for SSBJs have been analysed by the authors in Ref. [6] in the literature review stage. These values are assumed to be the appropriate initial requirements for environmentally friendly and economically viable SSBJs.

Table 1. Mission requirements for SSBJs

\begin{tabular}{l|r}
\hline Mission requirement & Value \\
\hline Range & $4000-4500 \mathrm{~nm}$ \\
\hline Cruise Mach number & $1.4-2.0$ \\
\hline Cruise altitude & $<17 \mathrm{~km}$ \\
\hline Seating capacity & $8-12$ \\
\hline Emission & $<15 \mathrm{gNO}_{\mathrm{x}} / \mathrm{kg}$ fuel \\
\hline Cumulative airport noise & $\sim 1400 \mathrm{~g} \mathrm{water} / \mathrm{kg}$ fuel \\
\hline Sonic boom intensity & Stage $4-10 \mathrm{~dB}$ \\
\cline { 2 - 2 } & $<0.5 \mathrm{psf}$ \\
\hline
\end{tabular}

\section{Propulsion Specification}

The function of the propulsion specification module is to input requirements regarding the propulsion systems of the vehicle. The propulsion specification module specifies the type of engine and fuel to use and the requirements for the propulsion system. There can be a combination of different type of propulsion systems for some hybrid power system. The hierarchy of the propulsion specification module is shown in Fig. 5. Each type of propulsion system represents a number of powerplants of the same size and performance, and it is recommended to specify similar powerplants as one system. 


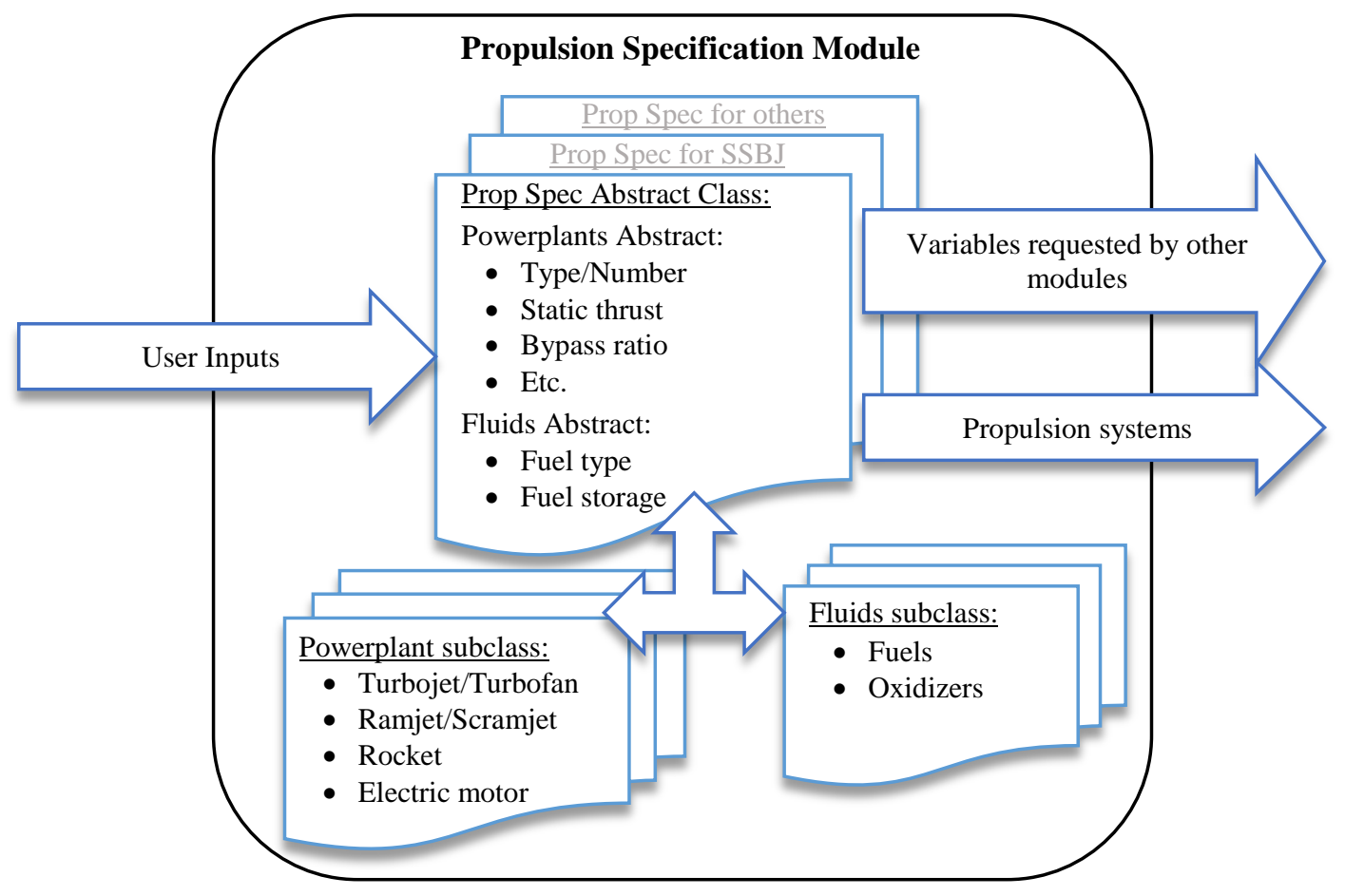

Fig. 5. Hierarchy and data flow of propulsion specification module

As with all aspects of supersonic aircraft design, the propulsion system is heavily constrained by numerous requirements. Better fuel efficiency is of high importance to improve the payload fraction and will contribute to a reduction of emissions. The engines defined here are two low-bypass ratio turbofans with afterburner.

\section{Propulsion Model}

The propulsion module calculates the engine performance at any flight conditions. The engine thrust and specific fuel consumption (SFC) are stored in two matrices. Users can extract the engine performance at given flight condition by interpolating the Thrust-Mach-Altitude-Throttle matrix and the SFC-Mach-Altitude-Throttle matrix. The hierarchy of this module is shown in Fig. 6. 


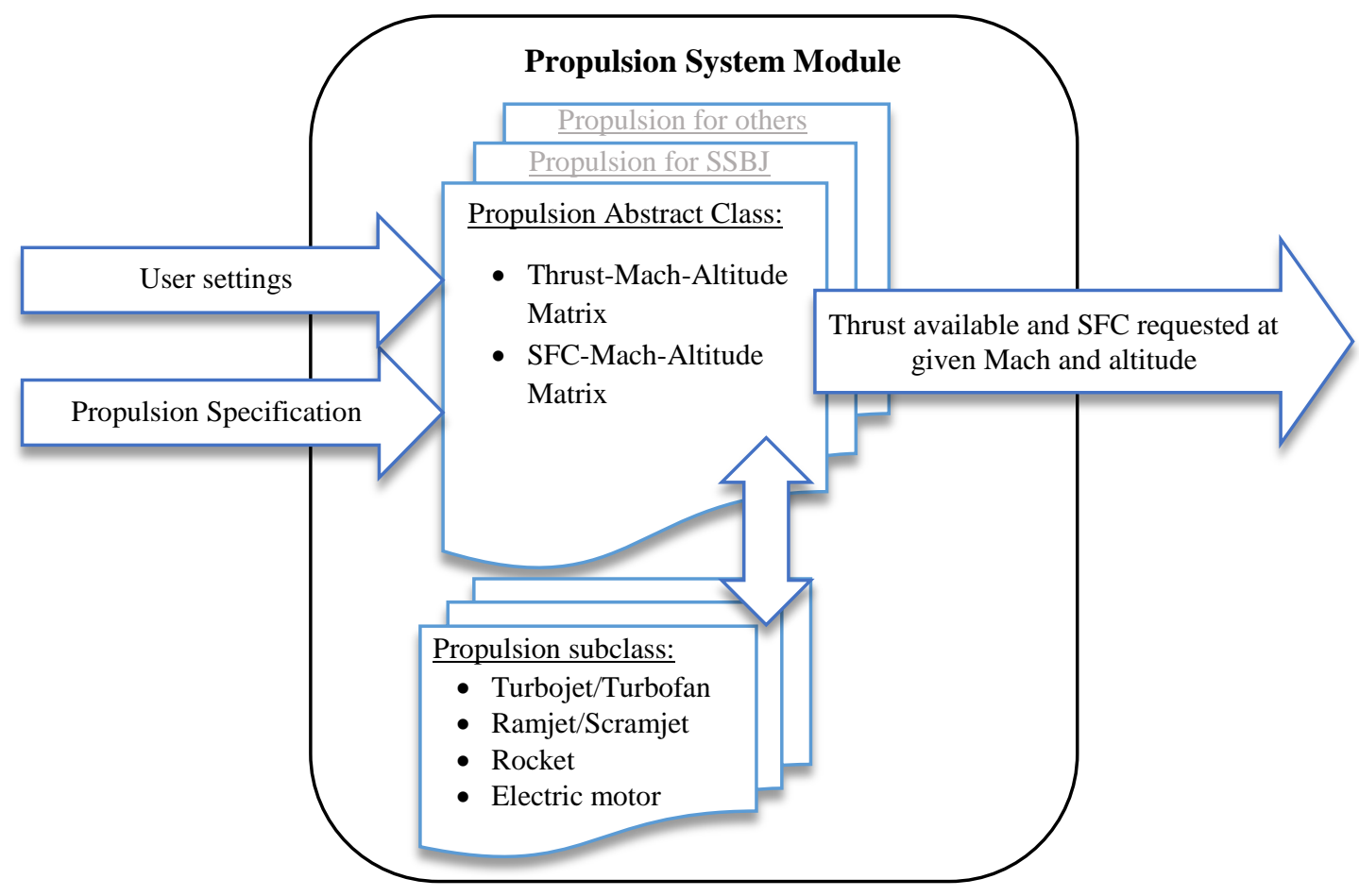

Fig. 6. Hierarchy and data flow of propulsion system module

The propulsion model for SSBJ design is a modified version of NASA EngineSim [8]. EngineSim calculates the engine performance based on engine parameters, including the geometry, material property, flight condition, throttle setting and so on. Design variables for each engine component are varied. The components and variables include the Inlet (pressure recovery), Fan (pressure ratio, efficiency, and bypass ratio), Compressor (CPR, compressor efficiency), Burner (fuel, maximum temperature, efficiency, pressure ratio), Turbine (turbine efficiency) and Nozzle (maximum temperature, efficiency, A8/A2). EngineSim defines the design point in design mode and then evaluates the off-design performance in test mode. In GENUS, the core of EngineSim is extracted instead of running the applet.

\section{E. Mass Breakdown}

The mass breakdown module provides a general framework estimating the mass of various components of an aircraft. Another important function of this module is to decouple the mass components from the packaging module that uses them. The mass component abstract class can be specified in the subclasses for the components of different aircraft. The hierarchy of the mass breakdown module is shown in Fig. 7. 


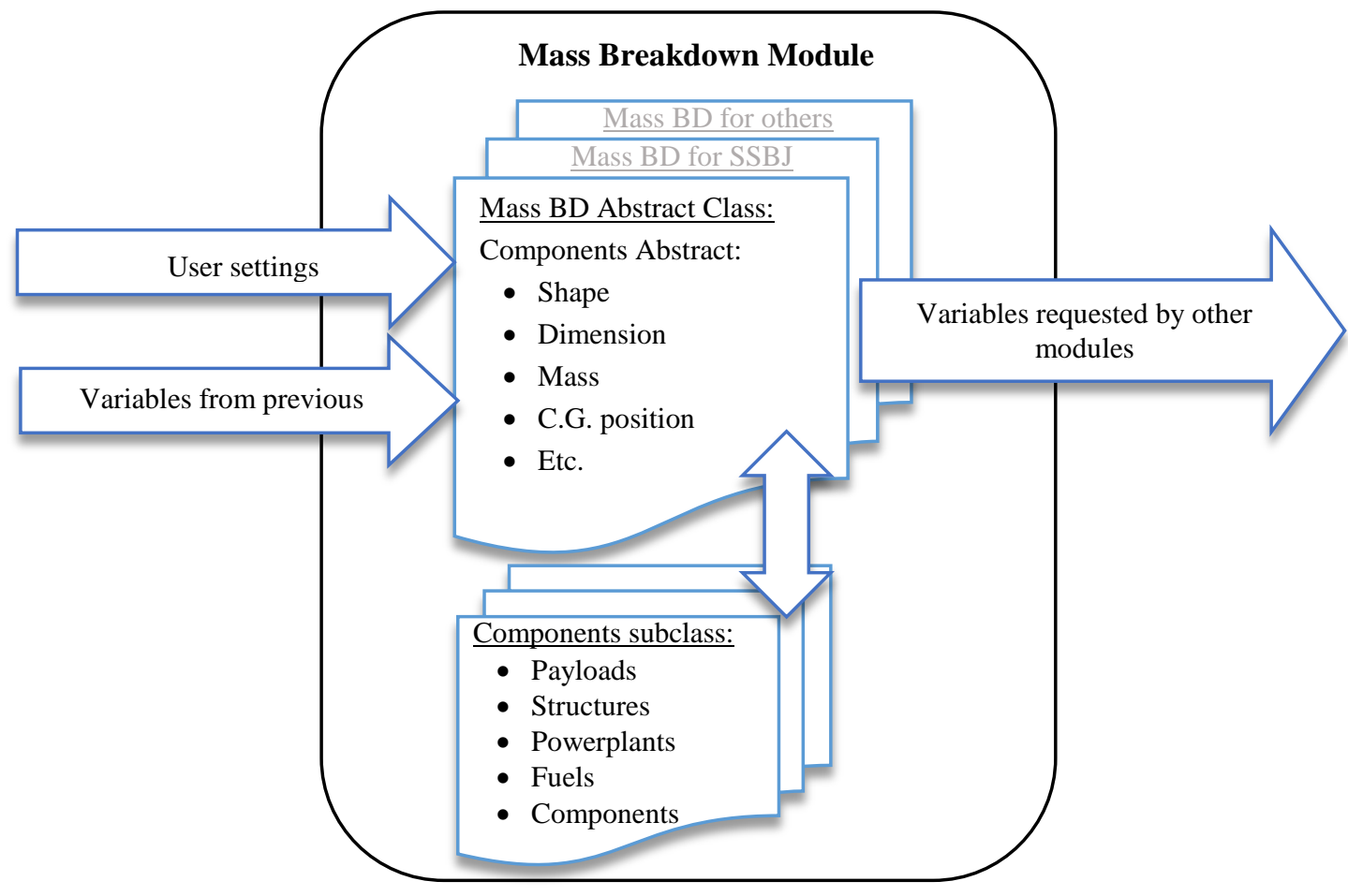

Fig. 7. Hierarchy and data flow of mass breakdown module

The mass estimation is one of the essential challenges for SSBJ design. It is important to define the start-cruise mass for sonic boom and aerodynamic analyses, which would impact the configuration design in turn.

At this stage, the empirical method is used in SSBJ design. There are several empirical methods available, Howe's mass prediction method [9], Raymer's mass prediction method [10], Torenbeek's method [11], Cranfield inhouse mass prediction method, etc. The method chosen is the Cranfield in-house mass prediction method. This method provides not only mass equations but also centre of gravity (CG) of each mass component, which is very useful to define the CG of the whole aircraft. The other mass prediction methods and other possible higher fidelity methods [12-14] will be tried in the future if time permits.

\section{F. Packaging}

Packaging is a novel and essential module in GENUS environment. The function of the packaging and CG module is, firstly, to position inner components to detect and avoid interference with other components and the external surface, secondly, to calculate the CG positions for various conditions (with and without fuel and payload). The CG positions are calculated by positioning the mass components from Mass Breakdown module and they are requested by the Stability module for longitudinal stability evaluation. The automated detection of interference is quite challenging. The hierarchy of this module is shown in Fig. 8. 


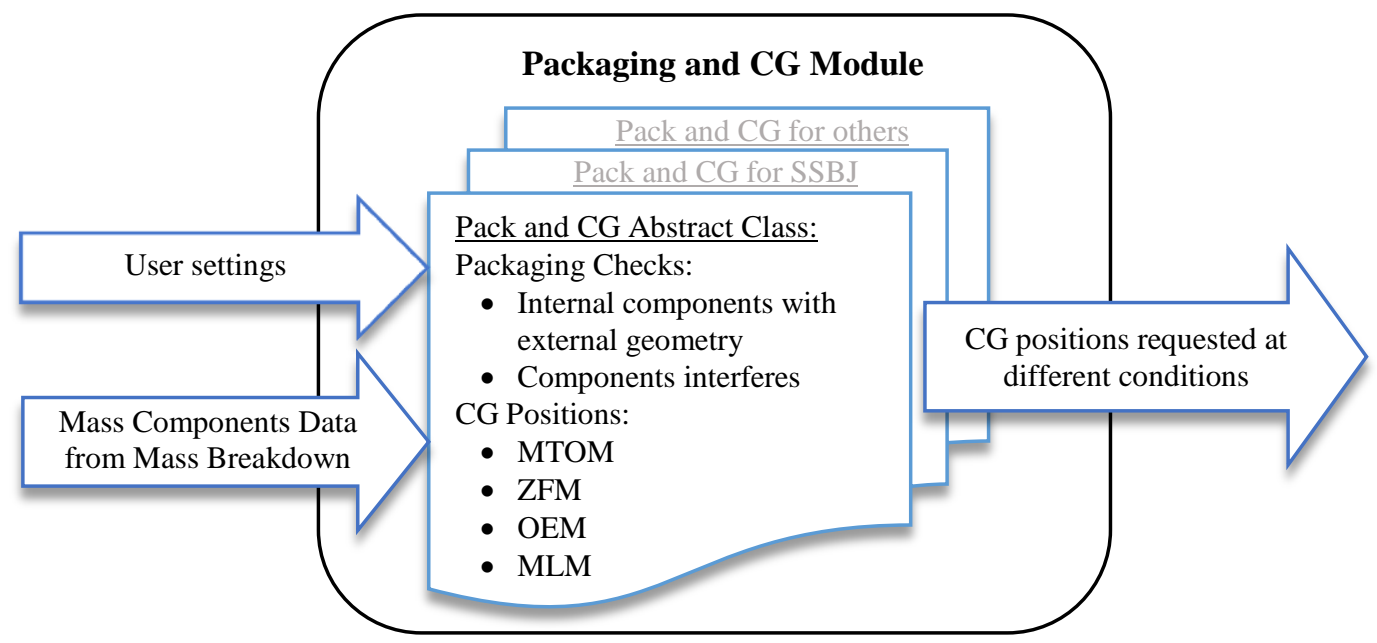

Fig. 8. Hierarchy and data flow of packaging module

Packaging is an important aspect for SSBJ design. The fuselage volume allocation is a big challenge. The internal items are arranged inside to achieve an area-ruled fuselage. The passenger cabin and the fuselage fuel tanks have the most influence on the volume distribution. An SSBJ cabin is designed typically accommodate 8-12 passengers. Under the category of comfort, the longer the flight time, the wider the cabin should be. Therefore, the relatively short travel time in an SSBJ should reduce the need for a larger cabin.

\section{G. Aerodynamic Analysis}

Aerodynamic analysis module is of vital importance in the aircraft conceptual design process. This module predicts the aerodynamic coefficients using the implemented analysis methods based on the flight conditions and specified geometry. The coefficient matrices are like a surrogate model, which calculate and store the coefficients at different Mach numbers and AOAs. Users can then extract the requested coefficients at specific Mach number and AOA by interpolating the matrices. The current hierarchy of the aerodynamic analysis module is shown in Fig. 9.

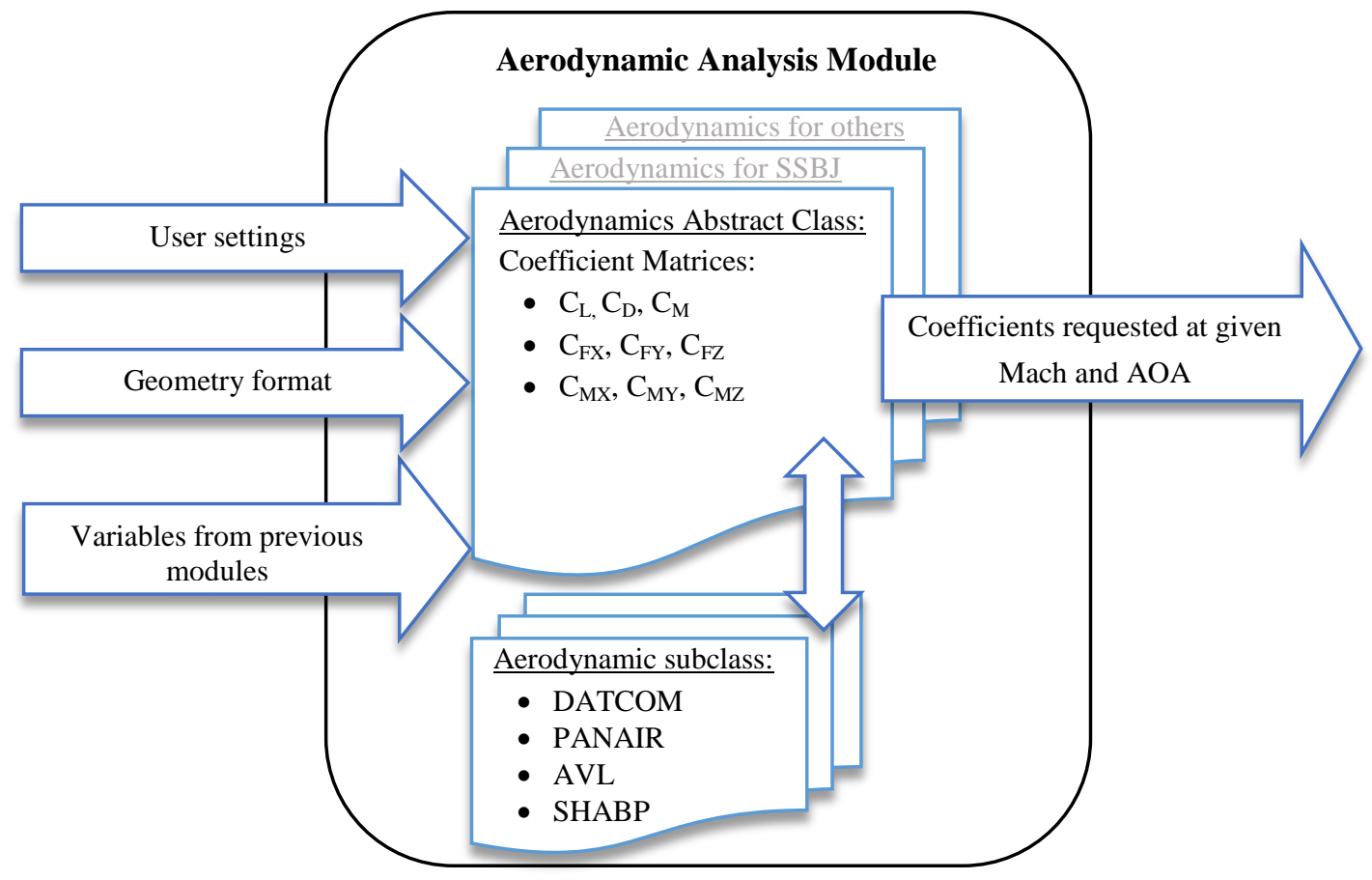

Fig. 9. Hierarchy and data flow of aerodynamic analysis module 
The aerodynamics module has the ability to provide the essential aerodynamic coefficients and runs automatically in the MDAO framework. Executable files cannot work for this purpose. The approach applied is to modify and compile the source code (FORTRAN) to a dynamic link library (DLL) file with a C/C++ wrapper. Fig. 10 illustrates the architecture of using Java Native Interface (JNI) to communicate between Java and C/C++.

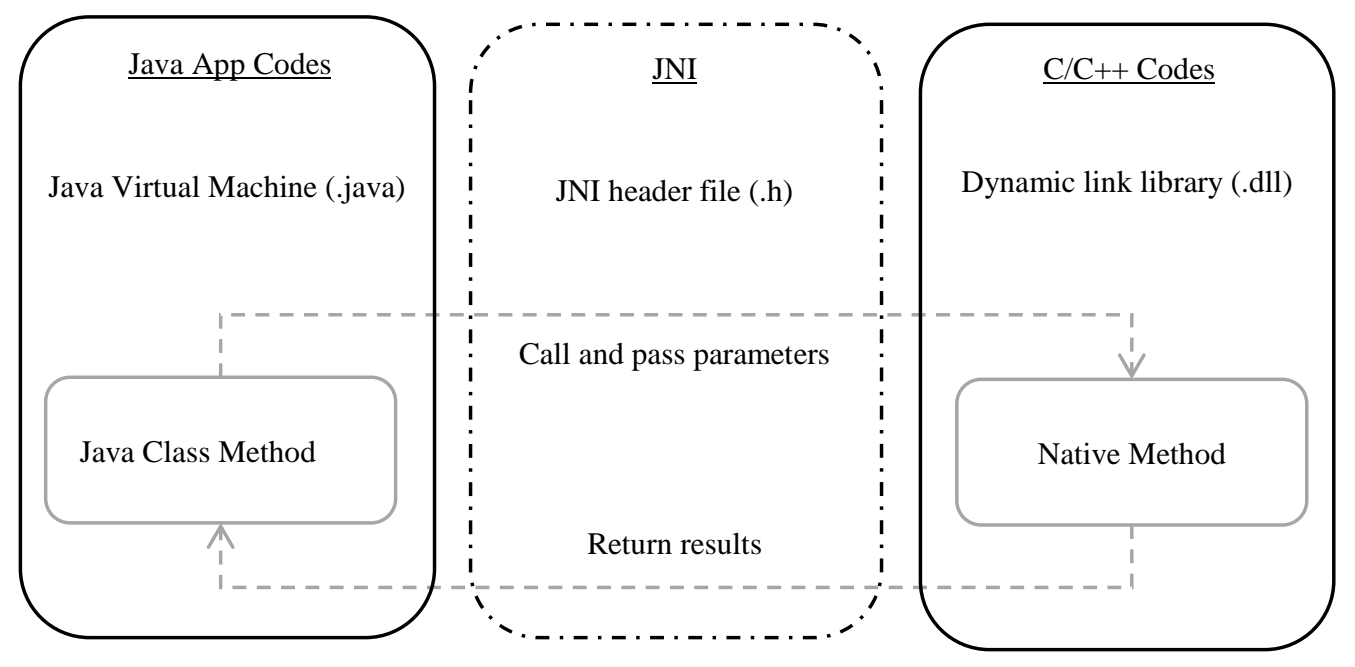

Fig. 10. Framework for integrating FORTRAN code into JAVA using JNI

The supersonic aircraft are a bit more complex to analyse for operating within different aerodynamic regimes. The aerodynamics module should have the ability to provide the essential aerodynamic coefficients for arbitrary geometry. The code has to be open source so that modifications can be made to run automatically in the MDAO framework.

The current aerodynamic analysis tools in GENUS include empirical methods from handbook [9, 10], digital DATCOM [15], vortex lattice method AVL [16], panel method PANAIR [17], and SHABP [18]. The capabilities of these aerodynamic analysis codes are listed in Table 2 . The empirical method needs to be expanded to supersonic speed regime to calculate the aerodynamics. The fidelity, however, is rather low. Digital DATCOM needs to equivalent the configuration to straight tapered surfaces. The problem with AVL method is that it only works for subsonic flow. On the other hand, the SHABP method is merely proper for Mach number between 1.5 and 25. The A502 solver/PANAIR is a higher order panel method for the computation of the aerodynamic characteristics of different aircraft configuration flying subsonically or supersonically (below Mach 4.0). This code is widely used in the SSBJ design cases [19-21]. The aerodynamic module is able to use different method at different Mach number. Therefore, these analysis tools can be combined to predict aerodynamic coefficients at subsonic, transonic, supersonic, and hypersonic speeds.

Table 2. Capabilities of different aerodynamic codes

\begin{tabular}{c|c|c|c|c|c|c}
\hline & Open source & $\begin{array}{c}\text { Arbitrary } \\
\text { Geometry }\end{array}$ & Subsonic & Transonic & Supersonic & Hypersonic \\
\hline DDATCOM & $\checkmark$ & $\times$ & $\checkmark$ & $\checkmark$ & $\checkmark$ & $\checkmark$ \\
\hline AVL & $\checkmark$ & $\times$ & $\checkmark$ & $\times$ & $\times$ & $\times$ \\
\hline PANAIR & $\checkmark$ & $\checkmark$ & $\checkmark$ & $\checkmark$ & $\checkmark$ & $\times$ \\
\hline SHABP & $\checkmark$ & $\checkmark$ & $\times$ & $\times$ & $\checkmark$ & $\checkmark$ \\
\hline
\end{tabular}

For the drag calculation, form factor method [22] is modified to calculate the skin friction and form drag. The result comes from the contribution of each component, as shown in Eq. (1)

$$
C_{D_{0}}=\sum_{j=1}^{N} \frac{F F_{j} C_{F_{j}} S_{w e t_{j}}}{S_{\text {ref }}}
$$

where $\mathrm{N}$ is the number of components used to model the configuration.

The wave drag by supersonic area rule [23] is applied for wave drag due to volume, as indicated in Eq. (2) and Eq. (3). 


$$
\begin{gathered}
D_{\text {wave }}(\theta)=-\frac{\rho V^{2}}{4 \pi} \int_{0}^{l} \int_{0}^{l} A^{\prime \prime}\left(x_{1}\right) \mathrm{A}^{\prime \prime}\left(x_{2}\right) \ln \left|x_{1}-x_{2}\right| \mathrm{d} x_{1} \mathrm{~d} x_{2} \\
D_{\text {wave }}=\frac{1}{2 \pi} \int_{0}^{2 \pi} D(\theta) d \theta
\end{gathered}
$$

\section{H. Performance Analysis}

The performance module gives the main outcomes of the conceptual design process. This module analyse whether a single instance of the design is capable of fulfilling the mission requirements. Field and point performances are assessed in this module. The inputs for the module are user setting for methods and variables from previous modules. The outputs are calculated results and error indicators between the results and target values. The calculated results can be the objective function in the optimizer and the error indicators can be used as constraints. The hierarchy and data flow of this module is shown in Fig. 11.

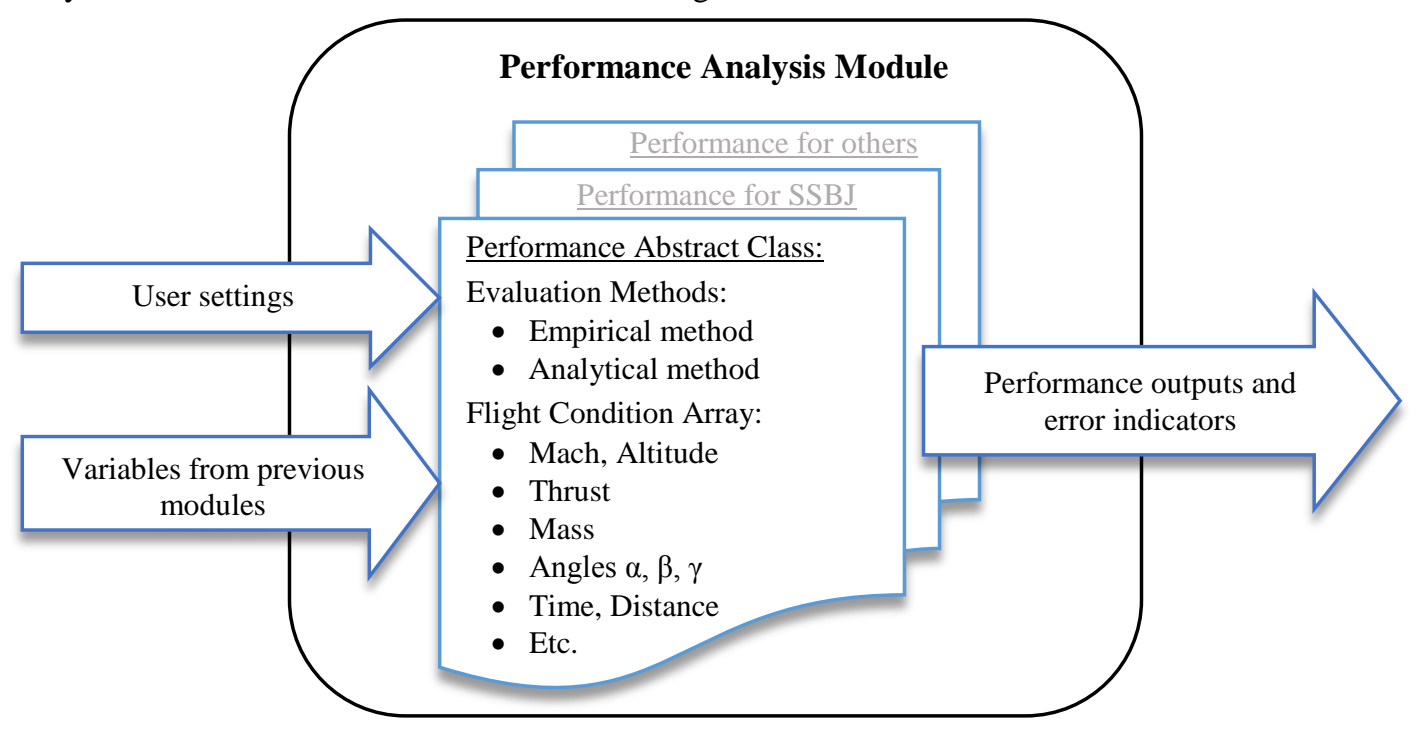

Fig. 11. Hierarchy and data flow of performance analysis module

In the SSBJ performance analysis module, the field and point performances are assessed. This module calculates the time, distance, thrust request, fuel consumption, flight path angle, lift and drag correction, etc. between mission profile points. ESDU Flight path optimization methods are applied for climbing, with the minimum specific excess power (Ps) at each energy height (He). Linearly varying Mach number climb/descent and transonic acceleration on dive are also used for performance trajectory.

\section{Stability and Control}

The stability and control module is designed to evaluate the stability characteristics and trim abilities of the aircraft at various flight conditions. This module does not provide inputs for any module but generates outputs that could be used to drive the optimisation process. These outputs are usually error indicators that state whether the aircraft is stable or not in a given flight condition, speed regime and/or the whole mission envelope. The hierarchy of this module is shown in Fig. 12. 


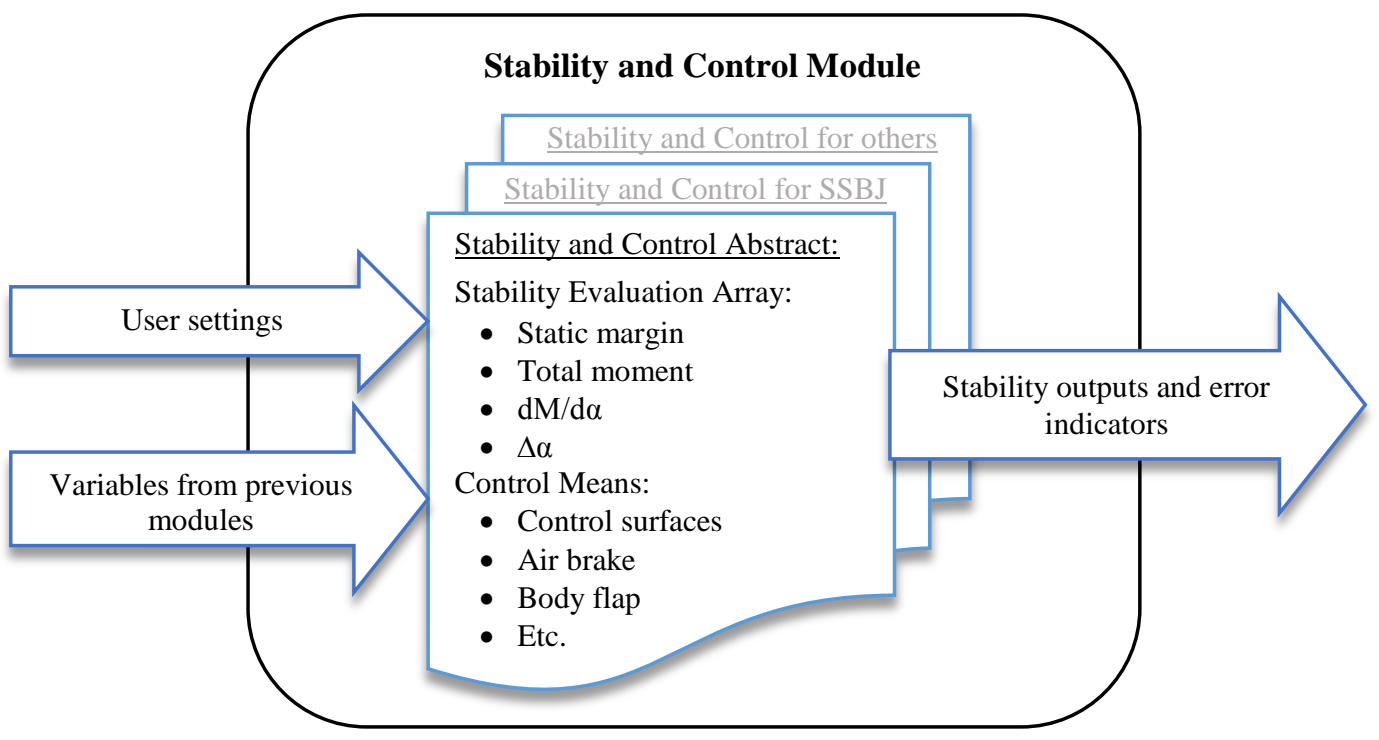

Fig. 12. Hierarchy and data flow of stability and control module

The longitudinal stability for an aircraft can be analysed by comparing the CG position from the packaging and CG module to the aerodynamic centre from the aerodynamic analysis module. The equation for static margin $\left(K_{n}\right)$ is as below.

$$
K_{n}=\frac{X_{a c}-X_{c g}}{\bar{c}}=-\frac{C_{m_{\alpha}}}{C_{L_{\alpha}}}
$$

To make the aircraft longitudinally static stable, the static margin $K_{n}$ has to be positive.

Eq. (4) provides an approach for the pitch control, to move the CG positions, which is also used by Concorde. One of the control means is to transfer the fuel to the forward and rear trim tanks to maintain the balance of the aircraft, as indicated in Fig. 13.

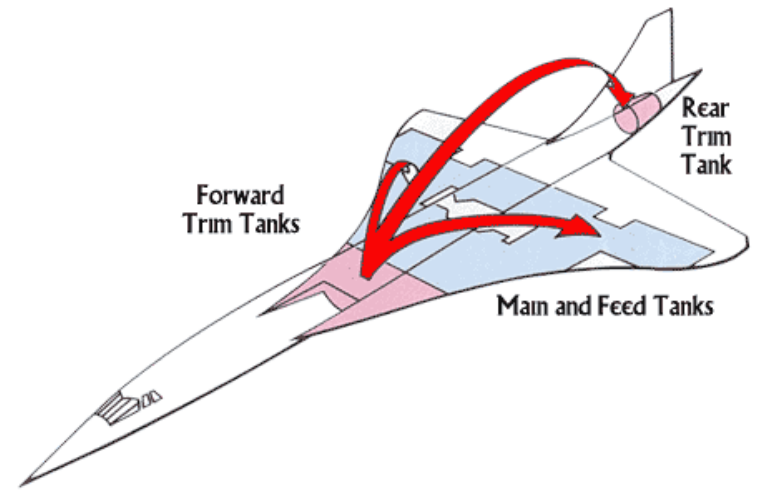

Fig. 13. Concorde trim tanks (Source: [37])

The dynamic stability needs to take the inertia forces and the damping forces into consideration, which have not been done yet.

\section{J. Sonic Boom Prediction}

Sonic boom prediction is one of the classes in special module. It is the most essential method for SSBJ design. Sonic boom prediction highly demands outcomes from the previous modules. There are usually two steps for sonic boom prediction, boom generation and boom propagation. Boom generation specifies the near-field pressure distribution through the volume distribution and lift distribution. Boom propagation is to propagate the sonic boom to the ground considering the nonlinear turbulence of the atmosphere. The hierarchy of special module is shown Fig. 14. 


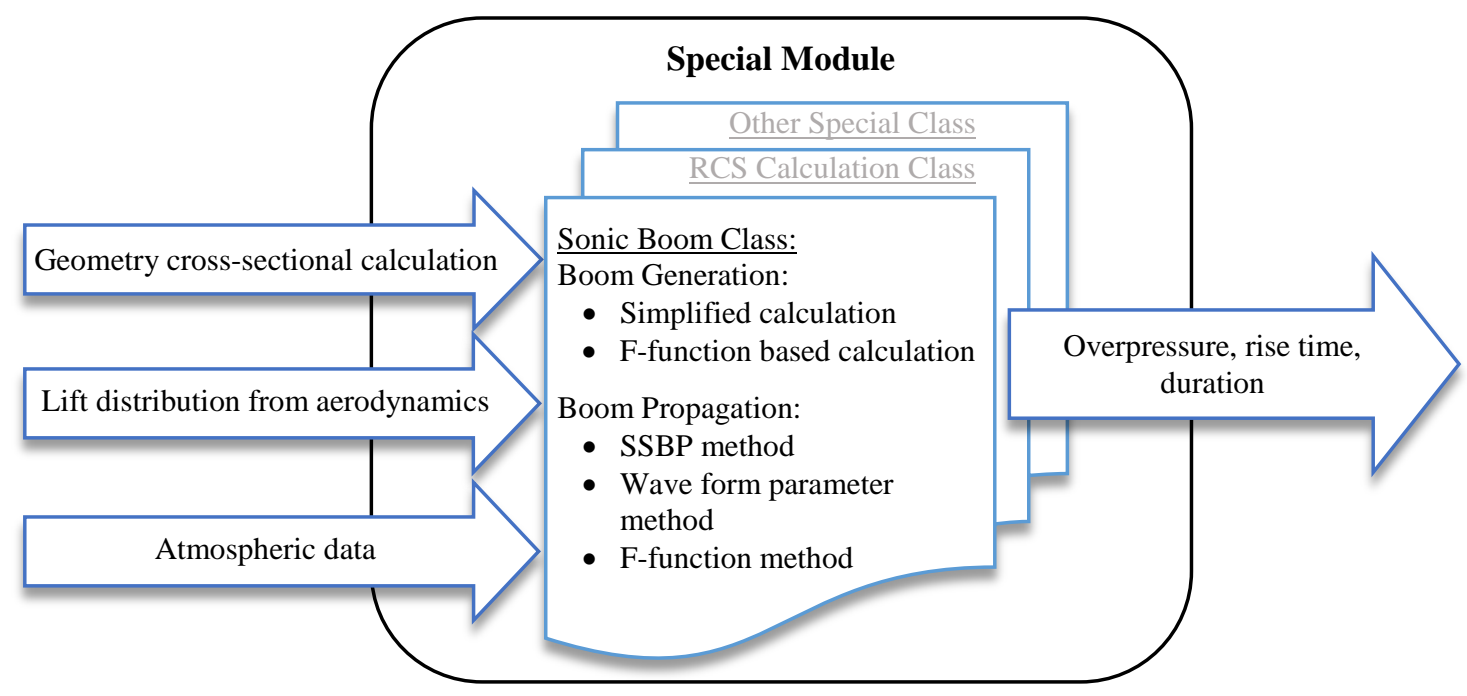

Fig. 14. Hierarchy and data flow of sonic boom prediction class

Sonic boom prediction is the biggest challenge for SSBJ design. There are basically three methods to predict sonic boom signature, Carlson simplified sonic boom prediction method [24], Thomas waveform parameter method [25], and the F-function based Hayes method [26]. They all need the near-field signature derived from the Ffunction, Eq. (5). The F-function depends on volume distribution and lift distribution, as indicated in Eq. (6) and Eq. (7) .

$$
\begin{gathered}
p \sqrt{\frac{c_{n}^{2} A}{\rho_{0} a_{0}^{3}}}=F(\xi) \\
F(x)=\frac{1}{2 \pi} \int_{0}^{x} \frac{A_{e}^{\prime \prime}(\bar{x})}{\sqrt{x-\bar{x}}} d \bar{x} \\
A_{e}(x, \theta)=A_{v}(x, \theta)+\frac{\beta}{2 q_{\infty}} \int_{0}^{x} L(x, \theta) d x
\end{gathered}
$$

The volume distribution is calculated using the Mach plane equation (Eq. (8)) intersecting with the parametric geometry. The chordwise lift distribution comes from the PANAIR code through the sectional property.

$$
x_{i}=x-\sqrt{M^{2}-1} y \cos \theta_{0}-\sqrt{M^{2}-1} z \sin \theta_{0}
$$

\section{K. Optimization}

Optimization is an essential approach for design space exploration. There are a range of optimization methods in aerospace design. However, there is no one that is suitable for all the problems. It is necessary to have several different optimizers. In GENUS, the optimizer gets objective function and constraints from the outputs. Optimization variables come from the user inputs. The optimization results are optimum objective value and corresponding variable values. The data flow of the optimization module is shown in Fig. 15. 


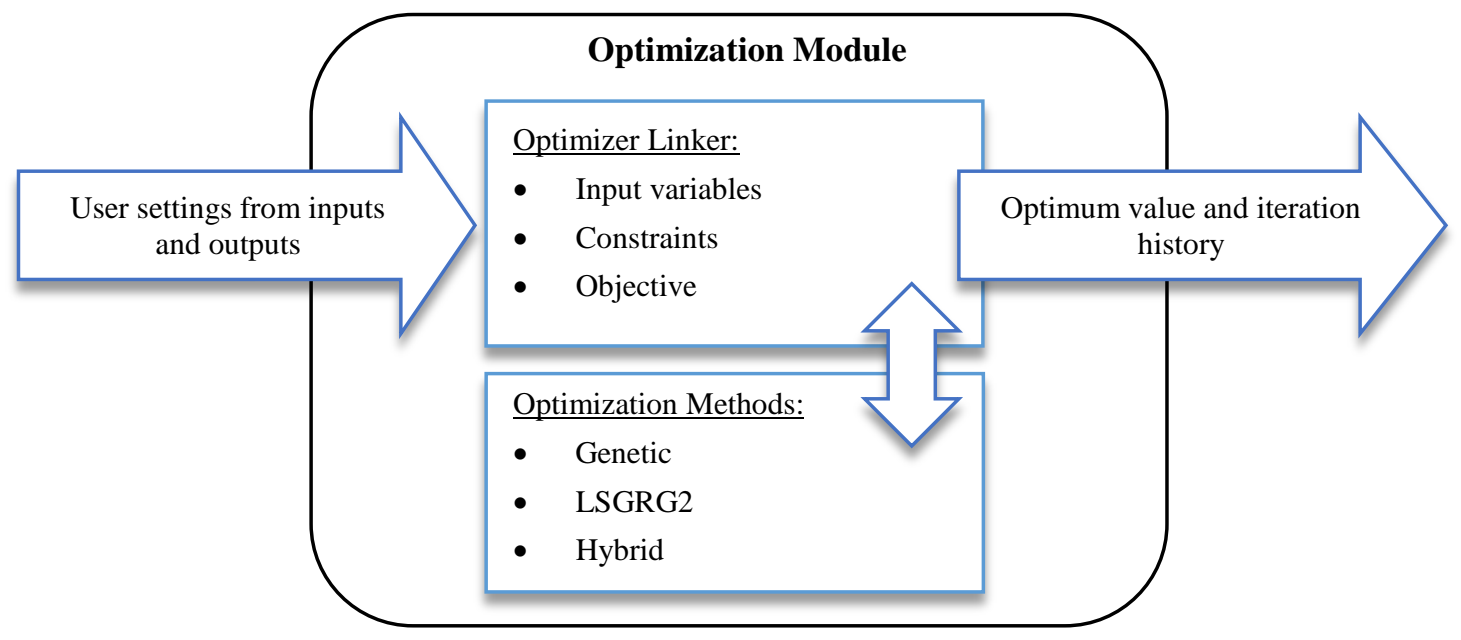

Fig. 15. Data flow of optimization module

For the SSBJ optimization, the objective function at this stage is sonic boom overpressure. This can help to explore the factors that will influence the sonic boom intensity. The optimization variables come from the user inputs which should make enough sense to all the disciplinary. The constraints are usually the error indicators to satisfy the design requirements and cross modules variables.

Multi-objective optimization algorithms can be implemented in the future. Supersonic drag minimization and sonic boom mitigation are the basic goals for SSBJ design. They can be both objectives so that the design space exploration can be more convincing.

\section{SSBJ Design and Analysis Results}

The design of the E5 Neutrino Supersonic Business Jet was carried out as the Group Design Project of the MSc students in Aerospace Vehicle Design in Cranfield University. A group of 30 students worked on this design over a period seven months. The scope of their efforts was broad and intended to provide a complete overview of the aircraft design process [27]. The general configuration of E5 SSBJ is shown in Fig. 16.

The geometry model of the SSBJ has to be fully parametric so that calculations (e.g. Mach plane cross-sectional area calculation) based on the geometry can be accurate. This aircraft features with highly swept wing and thin aerofoil to decrease supersonic wave drag. The slender fuselage helps to mitigate sonic boom intensity. The canard generates additional vortex lift especially on high angle of attack. 


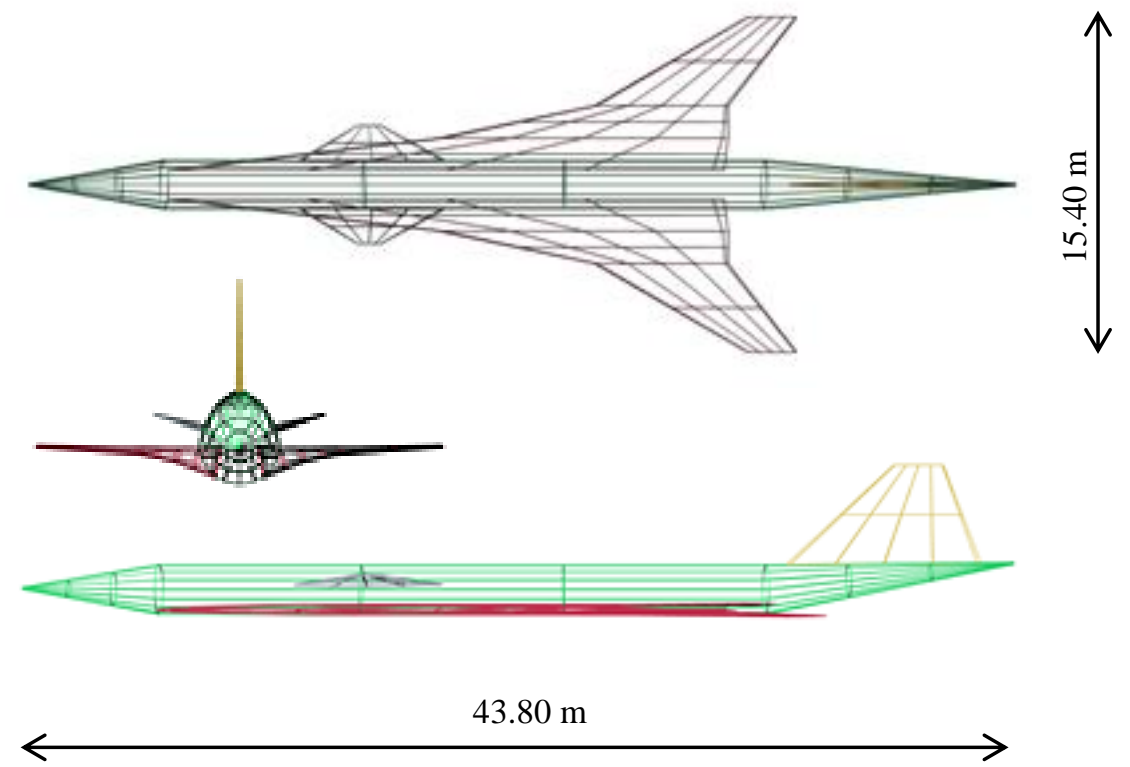

Fig. 16. Three view drawings of the E5 SSBJ

The mission requirements for the E5 SSBJ were proposed by Professor Howard Smith [28]. It is noted that an attractive SSBJ design would still need the usual attributes of safety, security, comfort, reliability, performance, and operational flexibility. The requirements are partially used in the GENUS design process as listed in Table 3.

Table 3. Mission requirements for E5 SSBJ

\begin{tabular}{l|c}
\hline Requirement & Value \\
\hline Estimated MTOW $(\mathrm{kg})$ & 45,454 \\
\hline Take-off distance $(\mathrm{m})$ & 3,000 \\
\hline Landing distance $(\mathrm{m})$ & 2,000 \\
\hline Cruise altitude $(\mathrm{m})$ & 15,000 \\
\hline Cruise Mach & 1.8 \\
\hline Target range $(\mathrm{km})$ & 8,334 \\
\hline Manoeuvre load factor & 2.5 \\
\hline Passenger number & 6 \\
\hline Crew number & 2 \\
\hline
\end{tabular}

The mission profile for a supersonic civil transport is more or less the same as subsonic transport, except for the transonic acceleration and supersonic cruise. The SSBJ climbs to an altitude and then dive to accelerate through the sound barrier, as the Concorde did. The aircraft then climbs to the cruise altitude at supersonic speed before cruising. A typical mission profile of an SSBJ is shown in Fig. 17. 


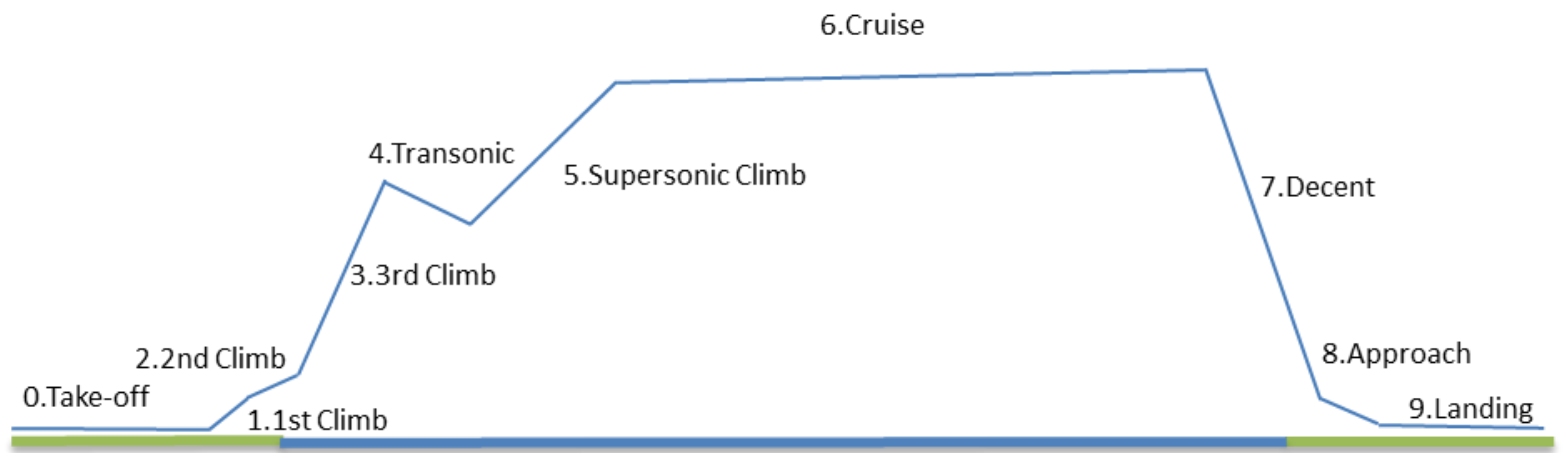

Fig. 17. Typical Mission Profile of an SSBJ

The mass breakdown of E5 SSBJ is shown in Fig. 18. The fuel accounts up to $60 \%$ of the total mass. The operational empty mass is about $38 \%$ of the total mass.

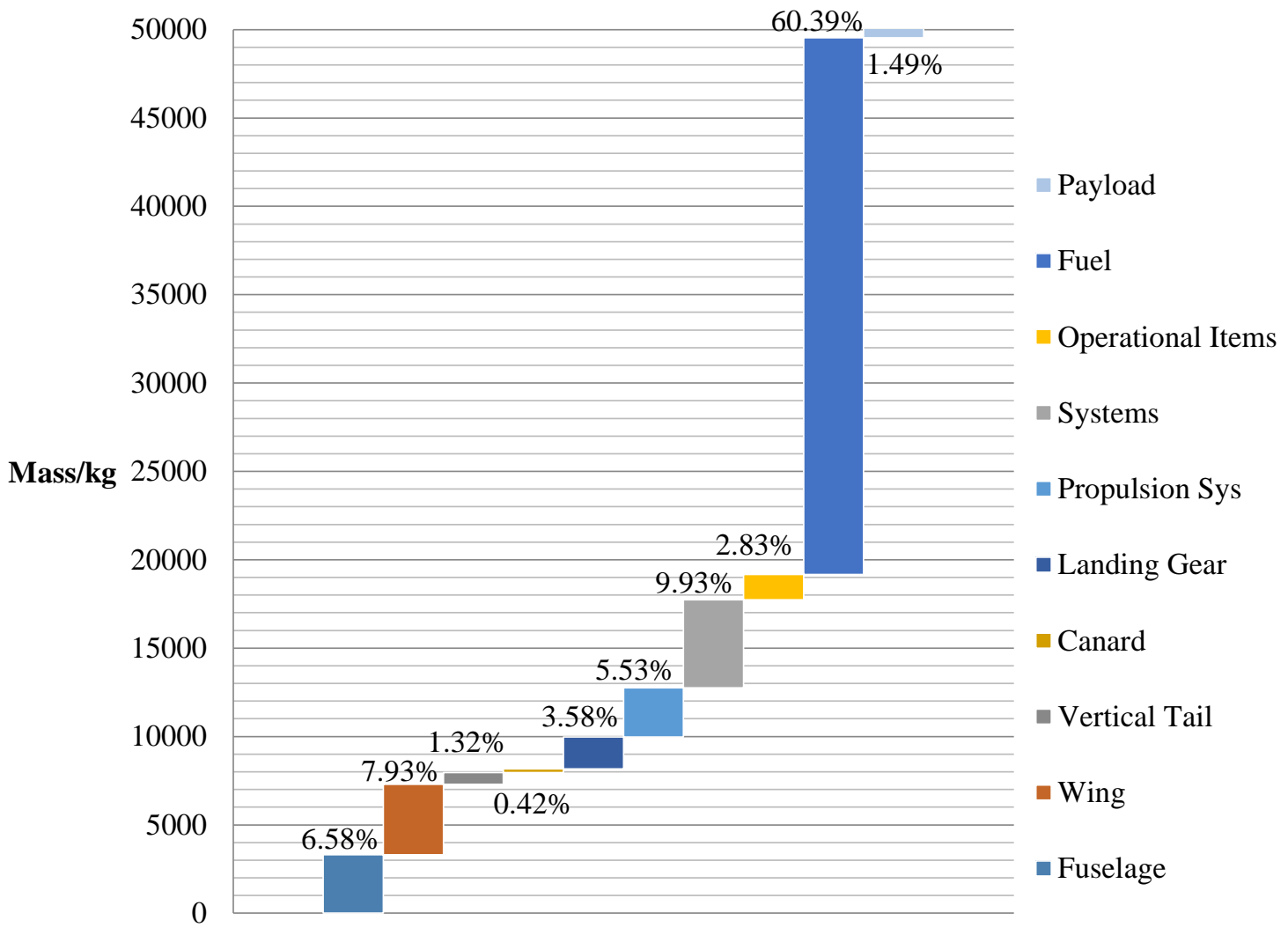

Fig. 18. Mass breakdown of E5 SSBJ

The engine for E5 SSBJ is a modified Eurojet EJ200 low-bypass turbofan. The propulsion specification is shown in Table 4.

Table 4. E5 SSBJ propulsion specification

\begin{tabular}{l|r}
\hline Variable Name & Value \\
\hline Fuel fraction & 0.668 \\
\hline Powerplant type number & Turbofan \\
\hline Powerplant type & 2 \\
\hline Powerplant number & 1 \\
\hline
\end{tabular}




\begin{tabular}{l|r}
\hline Sea level thrust $(\mathrm{kN})$ & 95 dry/142.5 reheat \\
\hline Wet over dry thrust & 1.5 \\
\hline Bypass ratio & 0.4 \\
\hline Design Mach number & 1.8 \\
\hline Design altitude & 15000 \\
\hline Mach limit & 2.5 \\
\hline Fuel type & Kerosene \\
\hline Fuel storage & Internal \\
\hline
\end{tabular}

The aerodynamic coefficients are calculated by the panel method PANAIR. The E5 SSBJ is designed with the Hybrid Laminar Flow Control (HLFC) technology, resulting in a laminar flow fraction of $50 \%-60 \%$ on the outer wing. The aerodynamic drag polar at subsonic and supersonic speeds are plotted in Fig. 19.

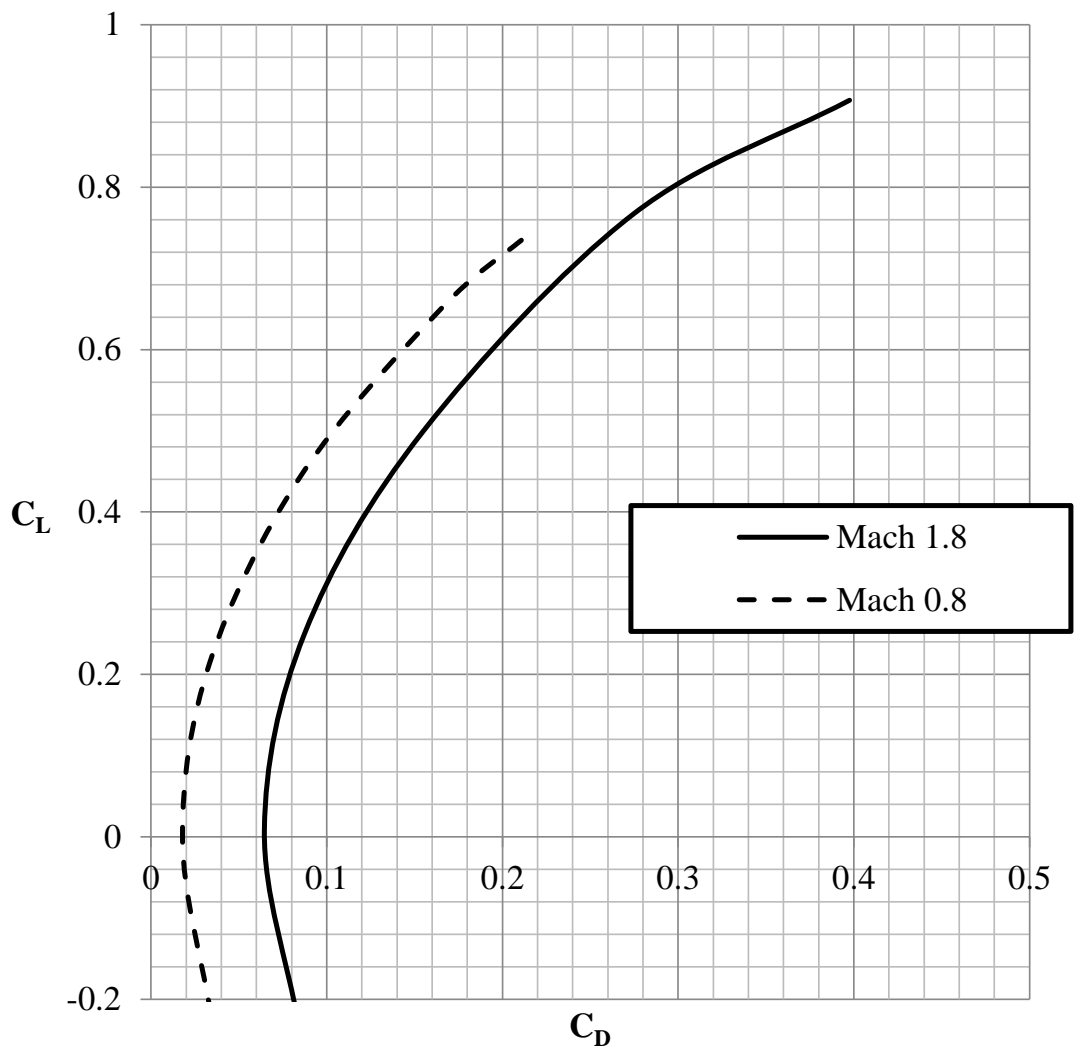

Fig. 19. E5 SSBJ Drag polar at subsonic and supersonic speeds

The arrangement of passenger cabin, payload, nose and main landing gear, propulsion system and so on are plotted in Fig. 20. 

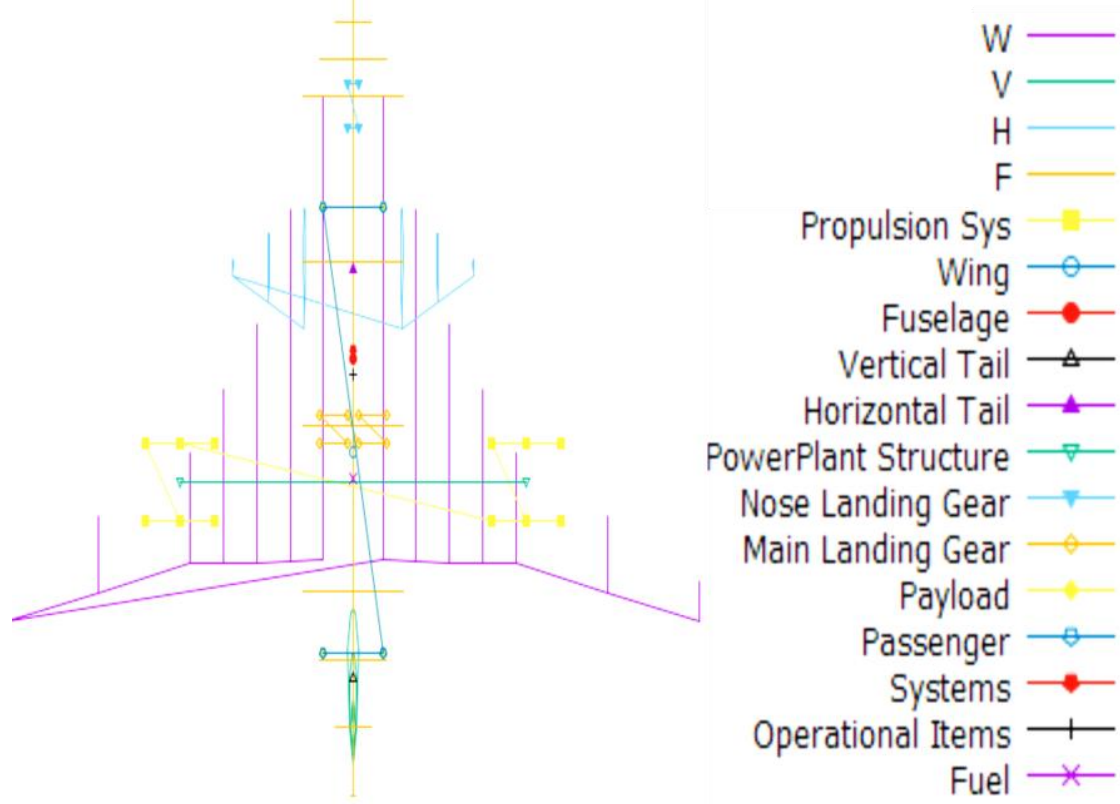

Fig. 20. E5 SSBJ packaging layout

The Mach plane cross-sectional distributions of different components are plotted in Fig. 21. The equivalent area due to lift accumulation comes from the PANAIR sectional properties. The Mach plane cross-sectional distributions are used for wave drag calculation and sonic boom prediction with Thomas waveform parameter method.

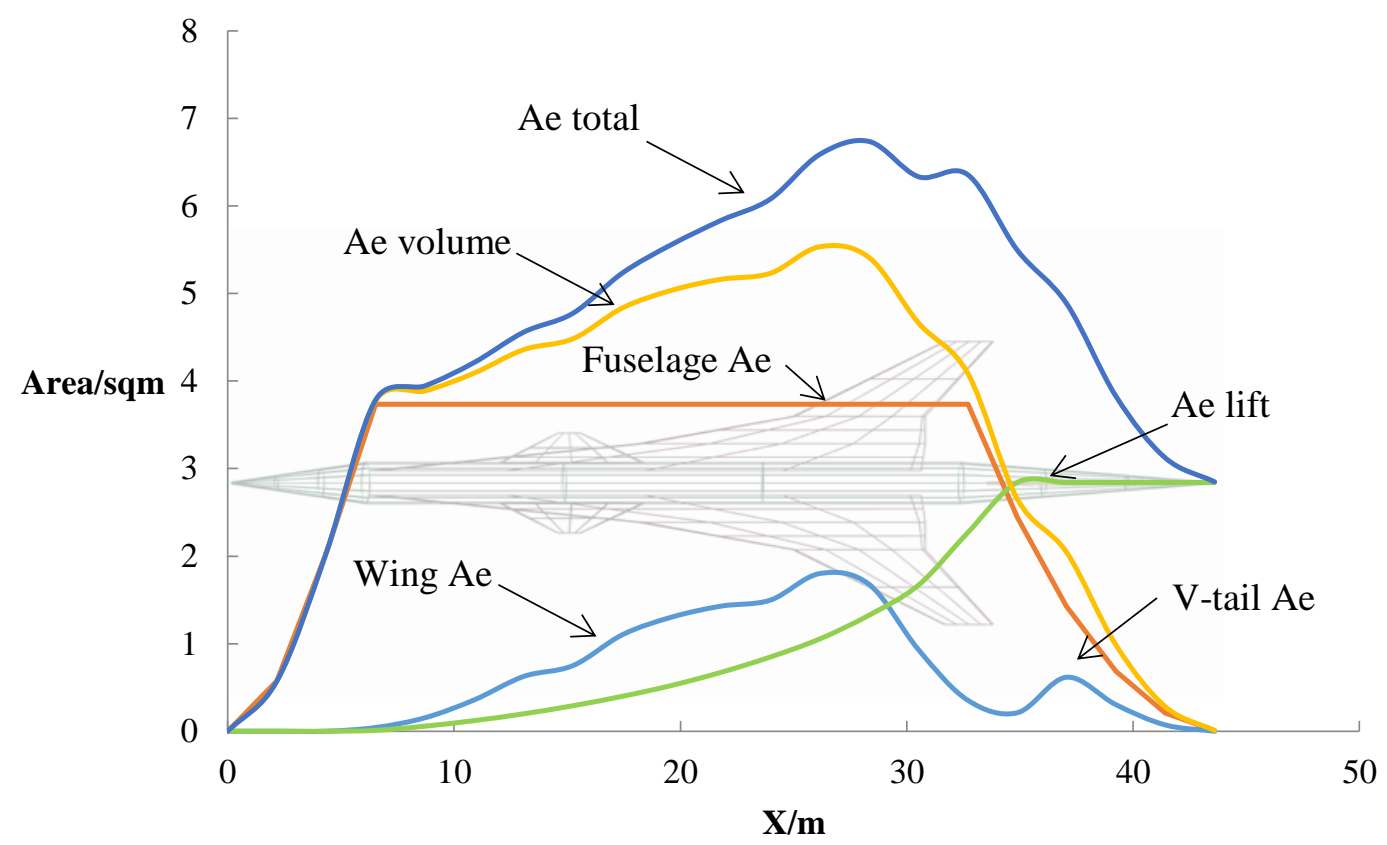

Fig. 21. E5 SSBJ Mach plane cross-sectional distribution

The sonic boom signature shown in Fig. 22 is predicted by Carlson simplified sonic boom prediction (SSBP) method. The Thomas waveform parameter method and F-function based Hayes method are under way. 


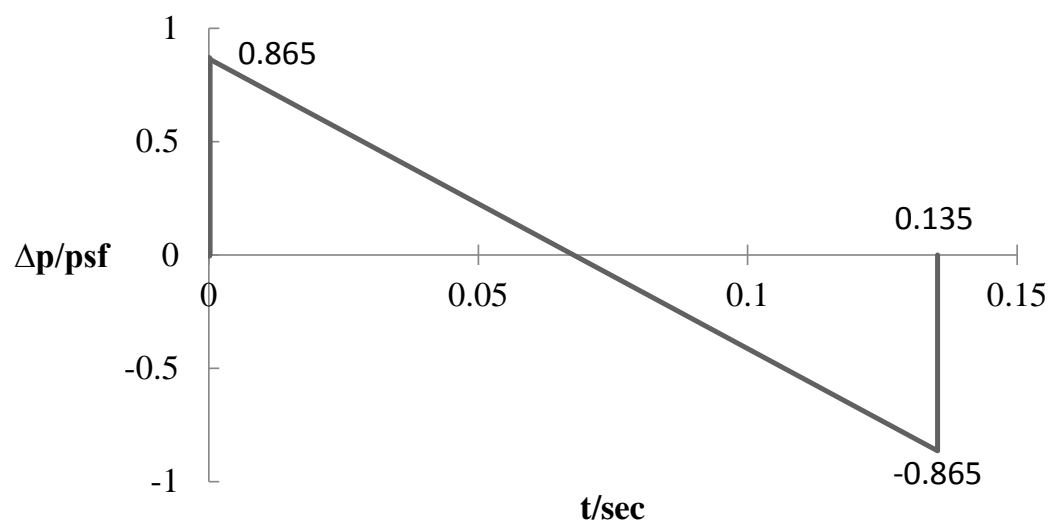

Fig. 22. Ground sonic boom signature predicted by SSBP method

\section{Conclusion}

In this paper we have introduced the GENUS aircraft conceptual design environment. GENUS is modular, expandable, flexible, independent, sustainable, and performable. The aim is to support knowledgeable aircraft designers with the overall design architecture and some analysis tools. The optimization module can be used for design space exploration. GENUS has been used for a hypersonic space design, a solar UAV design, a blended-wing body design, and a conventional airliner design.

The CENUS SSBJ model reuses the modules and common design methods from previous developers. It also creates major analysis methods appropriate to SSBJ design. These methods include:

- Mach plane cross-sectional area calculation based on the parametric geometry model.

- Automated aerodynamic analysis with PANAIR in both subsonic and supersonic speeds.

- Drag coefficient correction with Harris wave drag calculation and form factor method.

- NASA EngineSim integration for engine modeling.

- Sonic boom module with Carlson simplified sonic boom prediction method, Thomas waveform parameter method, and F-function based Hayes method.

The demonstration of Cranfield E5 SSBJ shows reasonable results in several disciplines. Low-boom and lowdrag SSBJ designs can be explored based on this SSBJ model.

Despite the efforts have been made on GENUS, there are still some aspects that need improving in the future. The geometry model needs to be expanded to cover more geometry. The propulsion module should contain more engine model including hybrid propulsion system. The PANAIR geometry format now works for conventional and several specific unconventional configurations. The stability and control module needs generic stability analysis and control means setting. The GENUS GUI should generally have the function to save optimizer setting and optimization results. In general, efforts to include different fidelity methods for each discipline are still needed.

\section{Acknowledgments}

The authors would like to thank Dr. David Sziroczak for providing help on the transition of PANAIR code and thank Mr. Eduardo Sepulveda palacios for the coding work on both PANAIR and EngineSim. Yicheng Sun is supported by the China Scholarship Council (CSC) to pursue his PhD degree in Cranfield University.

\section{References}

1. Smith, H., Sziroczák, D., Abbe, G. E., and Okonkwo, P. "The GENUS Aircraft Conceptual Design Environment," Unpublished Work, 2017.

2. Sziroczak, D. "Conceptual design methodologies appropriate to hypersonic space and global transportation systems," Aircraft Design Group. Vol. Ph.D., Cranfield University, UK, 2015.

3. Abbe, G. E. "Conceptual Design Methodologies for Small Solar Powered Unmanned Aerial Vehicle," Aircraft Design Group. Vol. Ph.D., Cranfield University, 2015.

4. Okonkwo, P. P. C. "Conceptual design methodology for blended wing body aircraft," Aircraft Design Group. Vol. Ph.D, Cranfield University, UK, 2016. 
5. Sun, Y., and Smith, H. "Turbofan Airliner Conceptual Design in Multidisciplinary Design Analysis Optimization Environment," 1st International Conference in Aerospace for Young Scientists. Beijing, P.R.China, 2016.

6. Sun, Y., and Smith, H. "Review and prospect of supersonic business jet design," Progress in Aerospace Sciences Vol. 90, 2016, pp. 12-38.

doi: https://doi.org/10.1016/j.paerosci.2016.12.003

7. Smith, H. "A review of supersonic business jet design issues," The Aeronautical Journal Vol. 111, No. 1126, 2007, pp. 761-776.

doi: https://doi.org/10.1017/S0001924000001883

8. $\quad$ "EngineSim Version 1.8a." NASA Glenn Research Center.

9. Howe, D. Aircraft conceptual design synthesis: Professional Engineering Publishing, 2000.

10. Raymer, D. P. Aircraft design: a conceptual approach. Reston, VA: AIAA, Inc., 1999.

11. Torenbeek, E., Jesse, E., and Laban, M. "Conceptual Design and Analysis of a Mach 1.6 Airliner," 10 th AIAA/ISSMO Multidisciplinary Analysis and Optimization Conference. 2004.

12. Mack, R. J. "A Rapid Empirical Method for estimating the gross takeoff weight of a high speed civil transport," NASA/TM- 1999-209535. Langley Research Center, Hampton, Virginia, 1999.

13. Harloff, G. J., and Berkowitz, B. M. "HASA: Hypersonic Aerospace Sizing Analysis for the preliminary design of aerospace vehicles," NASA-Contractor Report 182226. NASA Lewis Research Center, Cleveland, Ohio, 1988.

14. Winter, T., Márquez, J., and Scheneman, B. "Development of a Physics-Based Weight (PBWeight) Prediction Tool for Conceptual Design," AIAA Modeling and Simulation Technologies Conference. 2016, p. 4006.

15. Finck, R., and Hoak, D. USAF stability and control DATCOM: Engineering Documents, 1978.

16. $\quad$ "Athena Vortex Lattice." Vol. 2017.

17. Saaris, G. R., Tinoco, E., Lee, J., and Rubbert, P. "A502I User's Manual-PAN AIR Technology Program for Solving Problems of Potential Flow about Arbitrary Configurations," Boeing Document. 1992.

18. Gentry, A. E., Smyth, D. N., and Oliver, W. R. "The Mark IV Supersonic-Hypersonic Arbitrary-Body Program," AFFDL-TR-73-159. Air Force Dynamics Laboratory, 1973.

19. Choi, S., Alonso, J. J., and Kroo, I. M. "Two-level multifidelity design optimization studies for supersonic jets," Journal of Aircraft Vol. 46, No. 3, 2009, pp. 776-790.

doi: https://doi.org/10.2514/1.34362

20. Furukawa, T., and Makino, Y. "Conceptual Design and Aerodynamic Optimization of Silent Supersonic Aircraft at JAXA," 25th AIAA Applied Aerodynamics Conference. Miami, FL, 2007.

21. Choi, S., Alonso, J., Kroo, I., and Wintzer, M. "Multi-fidelity Design Optimization of Low-boom Supersonic Business Jets," 10th AIAA/ISSMO Multidisciplinary Analysis and Optimization Conference. Albany, New York, 2004.

22. Gur, O., Mason, W. H., and Schetz, J. A. "Full-configuration drag estimation," Journal of Aircraft Vol. 47, No. 4, 2010, pp. 1356-1367.

23. Harris, R. V. "An analysis and correlation of aircraft wave drag," NASATM X-947. National Technical Information Service, Hampton, 1964.

24. Carlson, H. W. "Simplified sonic-boom prediction," NASA Technical Paper 1122. Langley Research Center, Hampton, Virginia, 1978.

25. Thomas, C. L. "Extrapolation of sonic boom pressure signatures by the waveform parameter method," NASA TN D-6832. Ames Research Center, Moflett Field, California, 1972.

26. Hayes, W. D., Haefeli, R. C., and Kulsrud, H. "Sonic boom propagation in a stratified atmosphere, with computer program," NASA CR-1299. Langley Research Center, 1969.

27. Stocking, P. "E-5 Neutrino Supersonic Business Jet Project Executive Summery," 2005/2006 MSc Aerospace Vehicle Design. Cranfield University, 2005.

28. Smith, H. "E-5 Supersonic business jet: design specification." Cranfield University, 2005. 


\title{
Supersonic business jet conceptual
}

design in a multidisciplinary design

analysis optimization environment

\author{
Sun, Yicheng
}

AIAA

Sun $\mathrm{Y}$, Smith $\mathrm{H}$, Supersonic business jet conceptual design in a multidisciplinary design analysis optimization environment, Proceedings of 2018 AIAA/ASCE/AHS/ASC Structures, Structural Dynamics, and Materials Conference, AIAA SciTech Forum, 8-12 January 2018, Kissimmee, Florida, USA, Paper number AIAA 2018-1651

http:dx.doi.org/10.2514/6.2018-1651

Downloaded from Cranfield Library Services E-Repository 